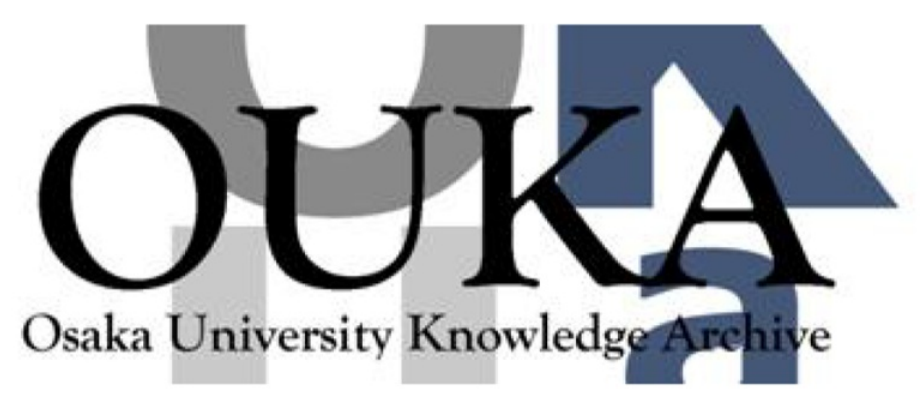

\begin{tabular}{|c|c|}
\hline Title & $\begin{array}{l}\text { Self-Assembly of Amphiphilic Amylose } \\
\text { Derivatives in Aqueous Media }\end{array}$ \\
\hline Author (s) & $\begin{array}{l}\text { Kameyama, Yuki; Kitamura, Shinichi; Sato, } \\
\text { Takahiro et al. }\end{array}$ \\
\hline Citation & $\begin{array}{l}\text { Langmuir: the ACS journal of surfaces and } \\
\text { colloids. } 35(20) \text { p. } 6719-\text { p. } 6726\end{array}$ \\
\hline Issue Date & $2019-04-30$ \\
\hline oaire:version & AM \\
\hline URL & https://hdl. handle. net/11094/81798 \\
\hline rights & $\begin{array}{l}\text { "This document is the Accepted Manuscript } \\
\text { version of a Published Work that appeared in } \\
\text { final form in Langmuir : the ACS journal of } \\
\text { surfaces and colloids, @ American Chemical } \\
\text { Society after peer review and technical editing } \\
\text { by the publisher. To access the final edited } \\
\text { and published work see } \\
\text { https://doi.org/10.1021/acs. langmuir. 9b00985." }\end{array}$ \\
\hline Note & \\
\hline
\end{tabular}

Osaka University Knowledge Archive : OUKA

https://ir. Library. osaka-u. ac. jp/

Osaka University 


\section{Self-Assembly of Amphiphilic Amylose Derivatives in Aqueous Media}

Yuki Kameyama, ${ }^{\dagger}$ Shinichi Kitamura, ${ }^{\ddagger}$ Takahiro Sato, ${ }^{\dagger}$ and Ken Terao ${ }^{* \dagger}$

'Department of Macromolecular Science, Graduate School of Science, Osaka University, 1-1, Machikaneyama-cho, Toyonaka, Osaka 560-0043, Japan.

Graduate School of Life and Environmental Sciences, Osaka Prefecture University, 1-1, Gakuencho, Nakaku, Sakai, Osaka 599-8531, Japan.

* Corresponding author. Tel.: +81 66850 5459; fax: +81 668505461 .

E-mail address: kterao@chem.sci.osaka-u.ac.jp

\section{ABSTRACT}

Six amylose derivative $\left(\mathrm{C}_{12} \mathrm{CMA}\right)$ samples with hydrophobic dodecyl ether groups and hydrophilic sodium carboxymethyl groups were synthesized from an enzymatically synthesized amylose for which weight-average molar mass is $50 \mathrm{~kg} \mathrm{~mol}^{-1}$ to realize amylose-based amphiphilic polymer micelles. The degree of substitution of hydrophobic $\left(D S_{\mathrm{C} 12}\right)$ and hydrophilic $\left(D S_{\mathrm{CM}}\right)$ groups ranges between 0.076 and 0.39 and between 0.35 and 1.83 , respectively. Static and dynamic light scattering, small-angle X-ray scattering (SAXS), and fluorescence measurements with pyrene as a probe were made for the samples in $150 \mathrm{mM}$ aqueous $\mathrm{NaCl}$ to characterize the higher order structure in solution. The fluorescence from pyrene showed that all six samples have hydrophobic environment while the hydrophobicity tends to increase with rising $D S_{\mathrm{C} 12}$. All six samples have high scattering intensity owing to the relatively large concentrated droplets ranging in the hydrodynamic radius from 50 to $110 \mathrm{~nm}$ whereas the weight fraction of such large particles is substantially small except for the highest $D S_{\mathrm{C} 12}$ sample. Most of polymer chains for relatively low $D S_{\mathrm{C} 12}$ of 0.076 were molecularly dispersed with very small amount of large droplets. The dispersed chain has somewhat smaller helix pitch per residue and more rigid main chain than those for amylose in dimethylsulfoxide, suggesting the amylosic main chain of $\mathrm{C}_{12} \mathrm{CMA}$ has helical structure with dodecyl groups at least locally. On the other hand, anisotropic shaped micelle-like structure is only found for relatively high $D S_{\mathrm{C} 12}(0.23$ and 0.39$)$ samples, which was detected by the SAXS profile at high $q$ range. Micelle structure for high $D S_{\mathrm{C} 12}$ samples is consistent with the high chain stiffness.

\section{Introduction}

Amylose, $\alpha-1,4$-glucan, behaves as rather flexible or semiflexible chains in solution including aqueous media ${ }^{1-4}$ while the main chain tends to form helical structure when it forms inclusion complex with some hydrophobic molecules. ${ }^{5}$ This complexation behavior is not only with iodine test but also many kinds of hydrophobic or amphiphilic molecules including alcohols and fatty acids with relatively long aliphatic chain. In many cases, the resultant complexes are not soluble in water and hence the structure is mainly investigated by diffraction methods for the crystal. ${ }^{6}$

Meanwhile, hydrophobically modified polysaccharides are widely investigated owing to its biomedical applications ${ }^{7-9}$ because they may form self-assembly structures including polymeric micelles or nanogels in aqueous solution. If we synthesize hydrophobically modified amylose, hydrophobic side groups both can form hydrophobic core or inclusion complex with its own main chain. Such hydrophobically modified amylose however is not soluble in water as in the case of 
complex with hydrophobic molecules taking the low solubility of amylose in water into consideration.

In this study, we thus synthesized doubly modified amylose which has hydrophilic carboxymethyl groups and hydrophobic dodecyl ether groups with different degree of substitution. The obtained chain conformation and/or complex formation behavior were determined in terms of the light and small-angle X-ray scattering methods as well as the fluorescence measurements with pyrene in $150 \mathrm{mM}$ aqueous sodium chloride.

\section{Experimental Section}

Amylose Sample. An enzymatically synthesized amylose sample (ESA50K) with no branching was used for this study. The viscosity-average molar mass $M_{\mathrm{v}}$ was estimated to be 49.7 $\mathrm{kg} \mathrm{mol}^{-1}$ from the intrinsic viscosity $[\eta]$ in dimethyl sulfoxide (DMSO) at $25{ }^{\circ} \mathrm{C}$ with the relationship between $[\eta]$ and the weight-average molar mass $M_{\mathrm{w}}$ reported by Nakanishi et al. ${ }^{2}$ This $M_{\mathrm{v}}$ value corresponds to the degree of polymerization of 307 calculated with the molar mass of the repeat unit of $0.162 \mathrm{~kg} \mathrm{~mol}^{-1}$. The dispersity index $Ð$ defined as the ratio of $M_{\mathrm{w}}$ to the numberaverage molar mass is less than 1.2 which was estimated from the phenylcarbamate derivative sample. $^{10}$

\section{Scheme 1. Synthesis of amphiphilic amylose, $\mathrm{C}_{12} \mathrm{CMA}$.}

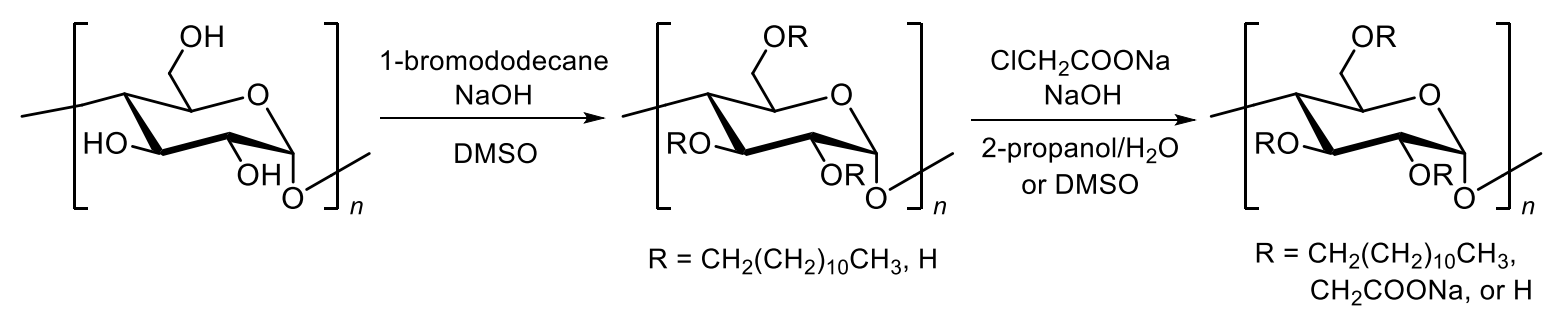

Synthesis of Partly Substituted Dodecylamylose. Three dodecyl amylose samples were synthesized in this study as a precursor of amphiphilic amylose derivatives. A typical procedure is as follows. ESA50K (5.0 g, $31 \mathrm{mmol}$ of the monomer unit) dried in a vacuum was dissolved into $500 \mathrm{~mL}$ of DMSO at $80{ }^{\circ} \mathrm{C}$ under an argon atmosphere. Note that DMSO was dried over calcium hydride just before use and the hydroxyl groups of the amylose were $93 \mathrm{mmol}$. Grinded sodium hydroxide ( $3 \mathrm{~g}, 75 \mathrm{mmol}$ ) was added to the solution and stirred for $1 \mathrm{~h}$ at room temperature. 1-Bromododecane $(18.5 \mathrm{~g}, 74 \mathrm{mmol})$ was added to the mixture and stirred for $18 \mathrm{~h} \mathrm{at} 70^{\circ} \mathrm{C}$. The reaction mixture was poured into a large amount of acetone to precipitate the obtained dodecylamylose. The precipitate was dried in a vacuum overnight. The yield was $3.4 \mathrm{~g} \mathrm{(64 \% ).}$ ${ }^{1} \mathrm{H}-\mathrm{NMR}$ measurements were made for the obtained samples in deuterated DMSO (DMSO- $d_{6}$ ) at $25{ }^{\circ} \mathrm{C}$ with a JEOL ECS-400 NMR spectrometer. The degree of substitution $D S_{\mathrm{C} 12}$ with dodecyl group was estimated to be $0.076,0.23$, and 0.39 for the three different samples from the area ratio of methyl proton $(0.84 \mathrm{ppm})$ on the dodecyl group to $\mathrm{C}-1$ proton $(5.14 \mathrm{ppm})$ on the main chain. Since the dispersibility in organic solvents substantially depends on $D S_{\mathrm{C} 12}$ as described later, it is suggested that dodecyl groups are randomly arranged on the amylosic main chain.

Carboxymethylation of the Dodecylamylose Samples. Amphiphilic amylose derivatives $\left(\mathrm{C}_{12} \mathrm{CMA}\right)$ were synthesized from carboxymethylation of the above mentioned dodecylamylose 
samples. The following is a typical procedure. Dodecylamylose $(1.5 \mathrm{~g}, 8.5 \mathrm{mmol}$ of the monomer unit) with $D S_{\mathrm{C} 12}=0.076$ was suspended into $15 \mathrm{~mL}$ of isopropanol containing $10 \%$ of water at 60 ${ }^{\circ} \mathrm{C}$ overnight with a magnetic stirrer under an Ar atmosphere. Grinded sodium hydroxide $(0.7 \mathrm{~g}$, $18 \mathrm{mmol}$ ) was added at room temperature and stirred for $30 \mathrm{~min}$ at $40{ }^{\circ} \mathrm{C}$. Sodium chloroacetate $(2.0 \mathrm{~g}, 17 \mathrm{mmol})$ was added to the reaction mixture and stirred for $4 \mathrm{~h}$ at $55^{\circ} \mathrm{C}$. The resultant yellow or brown colored viscous precipitant was dissolved in pure water, neutralized with acetic acid, and dialyzed into water with a regenerated cellulose membrane (molecular weight cut-off $\mathrm{MWCO}=12-14 \mathrm{~kg} \mathrm{~mol}^{-1}$ ). The aqueous solution of the $\mathrm{C}_{12} \mathrm{CMA}$ sample was frozen in a dryice methanol bath and lyophilized to obtain the sample as slightly yellow solid. The yield was 1.3 $\mathrm{g}(53 \%)$. It should be noted that DMSO was used for dodecylamylose with $D S_{\mathrm{C} 12}=0.23$ and 0.39 instead of isopropanol because they were hard to suspend into isopropanol. Six samples listed in Table 1 were prepared for the following scattering and fluorescence measurements.

Table 1. Molecular Characteristics and the Model Parameters of $\mathrm{C}_{12} \mathrm{CMA}$ samples in $\mathbf{1 5 0}$ $\mathrm{mM}$ aqueous $\mathrm{NaCl}$ at $25^{\circ} \mathrm{C}$

\begin{tabular}{|c|c|c|c|c|c|c|c|c|c|c|c|}
\hline Sample & $D S_{\mathrm{C} 12}$ & $D S_{\mathrm{CM}}$ & $\begin{array}{c}M_{0} / \\
\mathrm{kg} \\
\mathrm{mol}^{-1} \\
\end{array}$ & $\begin{array}{c}R_{\mathrm{H}, 1} \\
/ \\
\mathrm{nm} \\
\end{array}$ & $\begin{array}{c}R_{\mathrm{H}, 2} \\
/ \\
\mathrm{nm} \\
\end{array}$ & $\begin{array}{c}c_{\mathrm{sph}} w_{1} / \\
\mathrm{mg}^{-} \\
\mathrm{mL}^{-1}\end{array}$ & $\begin{array}{l}\left(1-w_{1}\right) M_{2} \\
/ \mathrm{kg} \mathrm{mol}^{-1}\end{array}$ & $\begin{array}{l}L / \\
\mathrm{nm}\end{array}$ & $\begin{array}{l}d / \\
\mathrm{nm}\end{array}$ & $\begin{array}{l}\lambda^{-1} / \\
\mathrm{nm}\end{array}$ & \\
\hline $\begin{array}{l}\mathrm{C}_{12} \text { CMA08- } \\
90\end{array}$ & 0.076 & 0.87 & 0.245 & 110 & 4.4 & 0.82 & 42 & 52 & 1.7 & 7.0 & \\
\hline $\begin{array}{l}\mathrm{C}_{12} \text { CMA08- } \\
140\end{array}$ & 0.076 & 1.43 & 0.289 & 97 & 4.0 & 0.42 & 40 & 37 & 1.7 & 8.5 & \\
\hline $\begin{array}{l}\mathrm{C}_{12} \mathrm{CMA08}- \\
180\end{array}$ & 0.076 & 1.83 & 0.321 & 61 & 4.3 & 0.57 & 44 & 36 & 1.7 & 9.0 & \\
\hline Sample & $D S_{\mathrm{C} 12}$ & $D S_{\mathrm{CM}}$ & 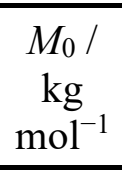 & $\begin{array}{c}R_{\mathrm{H}, 1} \\
/ \\
\mathrm{nm} \\
\end{array}$ & $\begin{array}{c}R_{\mathrm{H}, 2} \\
/ \\
\mathrm{nm} \\
\end{array}$ & $\begin{array}{c}c_{\mathrm{sph} w_{1}} / \\
\mathrm{mg} \\
\mathrm{mL}^{-1} \\
\end{array}$ & $\begin{array}{l}\left(1-w_{1}\right) M_{2} \\
/ \mathrm{kg} \mathrm{mol}^{-1}\end{array}$ & $\begin{array}{c}L_{\text {cyl }} \\
/ \\
\mathrm{nm} \\
\end{array}$ & $\begin{array}{c}d_{\text {cyl }} \\
/ \\
\mathrm{nm} \\
\end{array}$ & $f_{\mathrm{oi}} r_{\mathrm{oi}}{ }^{2}$ & $\sigma_{\mathrm{cyl}}$ \\
\hline $\begin{array}{l}\mathrm{C}_{12} \text { CMA23- } \\
35\end{array}$ & 0.23 & 0.35 & 0.229 & 50 & 9.9 & 0.44 & 430 & 35 & 7.0 & -0.20 & 0.4 \\
\hline $\begin{array}{l}\mathrm{C}_{12} \text { CMA23- } \\
90\end{array}$ & 0.23 & 0.87 & 0.270 & 54 & 5.4 & 0.48 & 65 & 12 & 5.5 & -0.30 & 0.5 \\
\hline $\begin{array}{l}\mathrm{C}_{12} \text { CMA39- } \\
90\end{array}$ & 0.39 & 0.86 & 0.297 & 68 & 5.6 & 12 & 137 & 14 & 5.3 & -0.28 & 0.5 \\
\hline
\end{tabular}

To determine the degree of substitution $D S_{\mathrm{CM}}$ of carboxymethyl group in terms of Heinze's method, ${ }^{11}$ we made ${ }^{1} \mathrm{H}-\mathrm{NMR}$ measurements for hydrolyzed sample with the following procedure. $\mathrm{A} \mathrm{C}_{12} \mathrm{CMA}$ sample (5 mg) was dissolved into deuterium oxide solution of $\mathrm{D}_{2} \mathrm{SO}_{4}(5 \mathrm{M}, 1 \mathrm{~mL})$ at $90{ }^{\circ} \mathrm{C}$ for $5 \mathrm{~h}$ to attain complete hydrolyzation all glucosidic bonds. A standard sample, 3- 
(trimethylsilyl)-1-propansulfonic acid sodium salt in deuterium oxide $(0.1 \%, 0.05 \mathrm{~mL})$, was added to the solution. ${ }^{1} \mathrm{H}-\mathrm{NMR}$ measurements were made for the resultant solution to estimate $D S_{\mathrm{CM}}$. It should be noted that number fraction of substituted position was estimated to be $0.5,0.1$, and 0.4 for C-2, C-3, and C-6 positions, respectively. Because this ratio is similar to that for sodium carboxymethylamylose ${ }^{12}$ from enzymatically synthesized amylose, substitution of carboxymethyl groups may be randomly occurred. Both the two degree of substitutions $D S_{\mathrm{C} 12}$ and $D S_{\mathrm{CM}}$ for hydrophobic and hydrophilic groups are listed in Table 1 along with the average molar mass $M_{0}$ per monosaccharide unit.

Preparation of Test Solutions. Each sample was dried in a vacuum at least for $24 \mathrm{~h}$ prior to prepare test solutions. While both SAXS and light scattering measurements were made for four solutions with different polymer mass concentration $c$ from 5 to $20 \mathrm{mg} \mathrm{mL}^{-1}$, each $\mathrm{C}_{12} \mathrm{CMA}$ sample was dissolved into pure water to prepare a solution with twice the highest concentration $(c=40$ $\mathrm{mg} \mathrm{mL}{ }^{-1}$ ). The resultant solution was kept at $90^{\circ} \mathrm{C}$ for $30 \mathrm{~min}$ and mixed with an identical volume of $300 \mathrm{mM}$ aqueous $\mathrm{NaCl}$ at room temperature to obtain test solution for which $c$ and ionic strength were $20 \mathrm{mg} \mathrm{mL}^{-1}$ and $150 \mathrm{mM}$, respectively. The solution was diluted with an appropriate amount of $150 \mathrm{mM}$ aqueous $\mathrm{NaCl}$ to prepare four solutions with different $c$ for each sample.

Light Scattering Measurements. Static and dynamic light scattering (SLS and DLS, respectively) measurements were made for the six $\mathrm{C}_{12} \mathrm{CMA}$ samples in $150 \mathrm{mM}$ aqueous $\mathrm{NaCl}$ at $25{ }^{\circ} \mathrm{C}$ with an ALV/SLS/DLS-5000 light scattering photometer (ALV, Germany) and vertically polarized incident light from an Nd:YAG laser $(250 \mathrm{~mW})$ for which wavelength $\lambda_{0}$ in a vacuum is $532 \mathrm{~nm}$. Specially designed light scattering cells with inner diameter of $14 \mathrm{~mm}$ or $7.8 \mathrm{~mm}$ were used in this study. Since slight fluorescence was found for some solutions, a band-pass filter at $\lambda_{0}$ $=532 \mathrm{~nm}$ (Edmond Optics: Half bandwidth $=10 \mathrm{~nm}$ ) was equipped between the solution cell and the detector which was calibrated with pure toluene as a reference material. The excess scattering intensity $R(q)$ at the magnitude $q$ of the scattering vector was determined from SLS measurements as functions of $q$ and $c$. Absorptive correction was applied for the obtained $R(q)$ value by the absorption coefficient as explained elsewhere ${ }^{13}$ in terms of the Lambert-Beer's law, that is at most $37 \%$ of the resultant $R(q)$. The specific refractive index increment $(\partial n / \partial c)_{\mu}$ at fixed chemical potential was determined for all samples in $150 \mathrm{mM}$ aqueous $\mathrm{NaCl}$ at $25^{\circ} \mathrm{C}$. Each solution was dialyzed for at least four days against the solvent (saline) with the same membrane as described above. The obtained $(\partial n / \partial c)_{\mu}$ at $\lambda_{0}=532 \mathrm{~nm}$ was between $0.116 \mathrm{~mL} \mathrm{~g}^{-1}\left(\mathbf{C}_{12} \mathbf{C M A 0 8 - 1 8 0}\right)$ and $0.144 \mathrm{~mL} \mathrm{~g}^{-1}\left(\mathbf{C}_{12} \mathbf{C M A 2 3 - 3 5}\right)$. These values were used to calculate the optical constant $K$ of SLS. The intensity autocorrelation function obtained by DLS measurements was analyzed by the CONTIN method to evaluate the spectrum $A\left(R_{\mathrm{H}, \mathrm{app}}\right)$ at the apparent hydrodynamic radius $R_{\mathrm{H} \text {,app, }}$ which was calculated from the relaxation time, solvent viscosity, and temperature by means of the Stokes-Einstein equation. The resultant $A\left(R_{\mathrm{H}, \mathrm{app}}\right)$ was bimodal for all samples as shown in Figure 1. They were almost independent of $c$, indicating that the weight ratio of the two components was independent of $c$. Two hydrodynamic radii, $R_{\mathrm{H}, 1}$ and $R_{\mathrm{H}, 2}$ for components 1 (large) and 2 (small), respectively, were thus determined for the five $\mathrm{C}_{12} \mathrm{CMA}$ samples and are listed in Table 1 . The scattering intensities $R_{1}(q)$ and $R_{2}(q)$ of the two modes calculated from $R(q)$ and $A\left(R_{\mathrm{H} \text {,app }}\right)$ with the method reported elsewhere ${ }^{14-15}$ taking into consideration that the ratio of $R_{1}(q)$ to $R_{2}(q)$ is identical to the area ratio of the two peaks in Figure 1. 


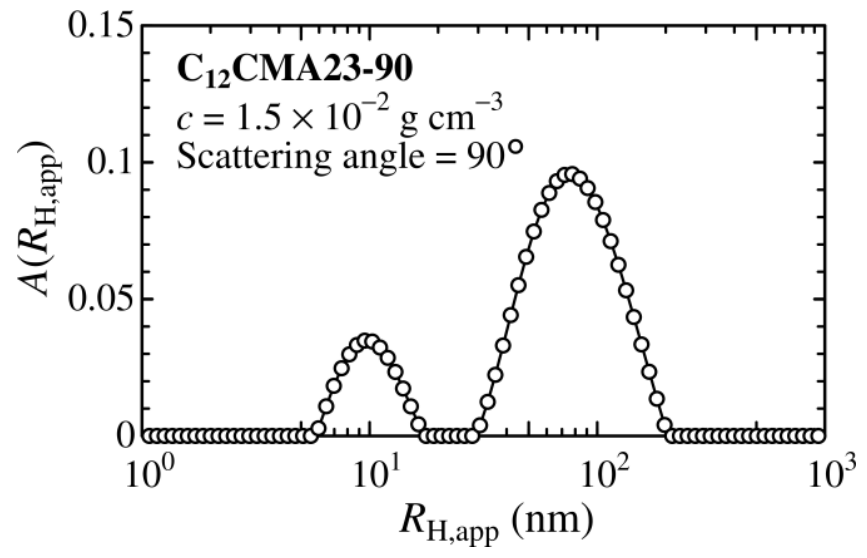

Figure 1. An example of DLS results for a C12CMA23-90 solution $\left(c=1.5 \times 10^{-2} \mathrm{~g} \mathrm{~cm}^{-3}\right)$ in $150 \mathrm{mM}$ aqueous $\mathrm{NaCl}$ at $25^{\circ} \mathrm{C}$ detected at the scattering angle of $90^{\circ}$.

Small-angle X-ray Scattering. SAXS measurements were made for the six $\mathrm{C}_{12} \mathrm{CMA}$ samples in $150 \mathrm{mM}$ aqueous $\mathrm{NaCl}$ at $25{ }^{\circ} \mathrm{C}$ at the BL40B2 beamline in SPring-8. Some preliminary measurements were also made at the BL-10C beamline in KEK-PF (data not shown in this paper). A quartz capillary cell filled with each solution or solvent was set to a thermostatic cell holder to determine the scattering image with a Rigaku R-AXIS VII imaging plate. The wavelength of incident light, camera length, and accumulation time was set to be $0.1 \mathrm{~nm}, 4 \mathrm{~m}$, and $180 \mathrm{sec}$, respectively. The actual camera length and the beam center on the imaging plate were determined by the Bragg reflection from silver behenate. The intensity of the direct beam was monitored by an ion chamber placed at the lower end of the cell both to calibrate the intensity of incident light and the transparency of each sample solution. A circular average procedure was employed for the obtained two-dimensional scattering data to evaluate the scattering intensity as a function of $q$. The scattering intensity of the solvent was subtracted from those of the solution at the same $q$ in the same capillary cell to determine the excess scattering intensity. Dilute solution of a polyethylene glycol sample $\left(M_{\mathrm{w}}=5.1 \mathrm{~kg} \mathrm{~mol}^{-1}\right)$ in pure water and/or a polystyrene sample $\left(M_{\mathrm{w}}=6.2 \mathrm{~kg} \mathrm{~mol}^{-1}\right)$ in 2-butanone was also measured in the same capillary cell to determine $R(q) / K$. Here, $K$ is the optical constant of the X-ray scattering and proportional to the square of the contrast factor $\Delta z$ defined as $\Delta z=z-\bar{v} \rho_{\mathrm{e}, \mathrm{s}} \cdot{ }^{16}$ Here, $z$ is the number of moles of electrons per unit mass of $\mathrm{C}_{12} \mathrm{CMA}, \bar{v}$ the partial specific volume of $\mathrm{C}_{12} \mathrm{CMA}$, and $\rho_{\mathrm{e}, \mathrm{s}}$ the electron density of the solvent. The value of $\bar{v}$ was determined from the specific density increment for the dialyzed solution which was used to determine $(\partial n / \partial c)_{\mu}$ to estimate the contrast factor at fixed chemical potential. The resultant $\Delta z$ value was between $0.129 \mathrm{~mol} \mathrm{~g}^{-1}\left(\mathbf{C}_{12} \mathbf{C M A 3 9 - 9 0}\right)$ and $0.187 \mathrm{~mol} \mathrm{~g}^{-1}$ (C12 CMA08-180).

Fluorescence of Pyrene as a Probe of Hydrophobicity. To estimate hydrophobic environment in solution, steady-state fluorescence measurements for the $\mathrm{C}_{12} \mathrm{CMA}$ samples with pyrene as a probe were made on a Hitachi F-4500 fluorescence spectrometer. At most $5 \mu \mathrm{L}$ of concentrated methanol solution of pyrene was added to $3 \mathrm{~mL}$ of aqueous solution of $\mathrm{C}_{12} \mathrm{CMA}$ ( $c$ $=5 \mathrm{mg} \mathrm{mL}^{-1}$ ) including $150 \mathrm{mM} \mathrm{NaCl}$, sonicated for $60 \mathrm{sec}$ with an ultrasonic cleaner, heated at $90{ }^{\circ} \mathrm{C}$ for $30 \mathrm{~min}$, and stirred over night at room temperature prior to the fluorescence measurements. The fluorescence from $\mathrm{C}_{12} \mathrm{CMA}$ molecules were subtracted with the aid of the fluorescence spectra for the $\mathrm{C}_{12} \mathrm{CMA}$ solution without pyrene. Molar concentration of pyrene [Py] was determined from the absorbance which was measured by a JASCO V-550 UV/VIS 
spectrometer at $\lambda_{0}=337 \mathrm{~nm}$. At least three different [Py] was chosen for each $\mathrm{C}_{12} \mathrm{CMA}$ sample. The resultant range of [Py] was between $0.6 \mu \mathrm{M}$ and $30 \mu \mathrm{M}$. The obtained ratio $I_{3} / I_{1}$ of intensities of the third $\left(\lambda_{0}=383 \mathrm{~nm}\right)$ to the first $\left(\lambda_{0}=372 \mathrm{~nm}\right)$ vibronic peaks for the pyrene are almost independent of $[\mathrm{Py}]$, within at most $\pm 5 \%$. As a reference, similar measurement for a sodium carboxymethyl amylose $\left(\mathrm{NaCMA}, D S_{\mathrm{CM}}=1.35\right)$ synthesized from ESA50K was also conducted. The $[\mathrm{Py}]$ was from 0.024 to $0.76 \mu \mathrm{M}$.

\section{Results and Discussion}

Scattering Profile for the $\mathrm{C}_{12} \mathrm{CMA}$ Samples with a Few Hydrophobic Groups. Normalized scattering intensity $R(q) / K c$ at high $q$ range is almost independent of $c$ in the investigated range $\left(5 \mathrm{mg} \mathrm{mL}^{-1}<c<20 \mathrm{mg} \mathrm{mL}^{-1}\right.$ ), indicating local structure is substantially the same in this concentration range. We thus plot the extrapolated value $[R(q) / K c]_{c \rightarrow 0}$ to $c=0$ against $q$ for $\mathbf{C}_{\mathbf{1 2}} \mathrm{CMA08-90,} \mathbf{C}_{\mathbf{1 2}} \mathrm{CMA08-140}$, and $\mathbf{C}_{\mathbf{1 2}} \mathrm{CMA08-180}$ in Figure 2 to avoid interparticle interference effects. It should be noted that the concentration dependence of $R(q) /$ $K c$ is negligibly small in the scale of the figure. The obtained $[R(q) / K c]_{c \rightarrow 0}$ data from the SAXS measurement (unfilled circles) mostly approach $\left[R_{2}(q) / K c\right]_{c \rightarrow 0}$ from SLS (triangles) with lowering $q$, where $R_{2}(q)$ means the normalized scattering intensity from smaller particles as defined in the experimental section. This means that the scattering intensity $R_{1}(q)$ from larger particles (component 1) decreases rapidly with increasing $q$ and becomes negligible in the $q$ range of SAXS, suggesting the weight fraction of component 1 is negligibly smaller than that for the component 2 .

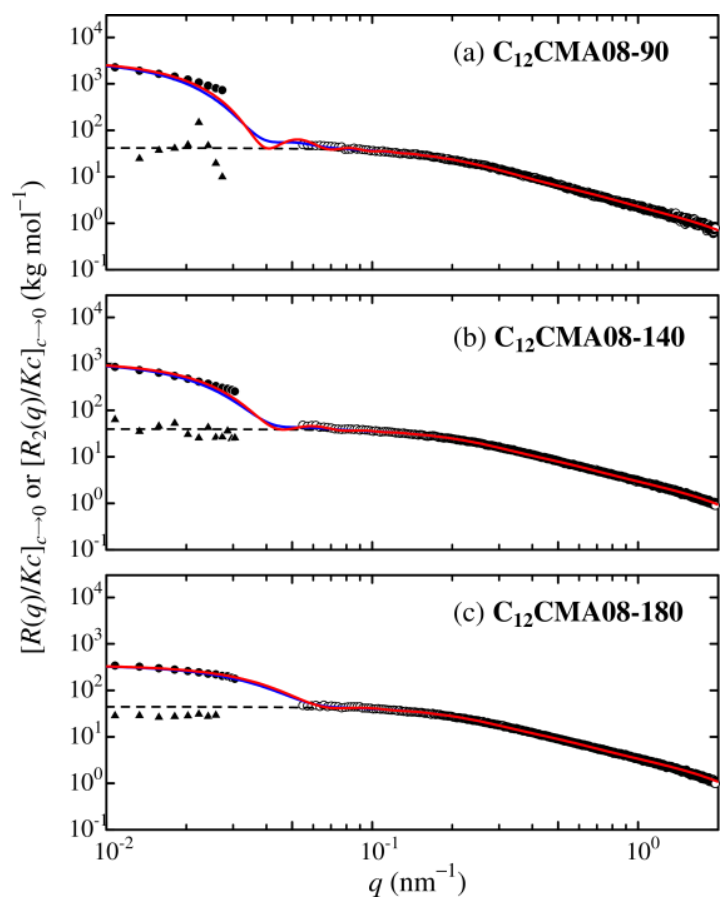

Figure 2. Magnitude $q$ of the scattering vector dependence of $[R(q) / K c]_{c \rightarrow 0}$ (circles) and $\left[R_{2}(q) / K c\right]_{c \rightarrow 0}$ (triangles) for relatively hydrophilic $\mathrm{C}_{12} \mathrm{CMA}$ samples in $150 \mathrm{mM}$ aqueous $\mathrm{NaCl}$ at $25{ }^{\circ} \mathrm{C}$. (a) $\mathrm{C}_{12} \mathrm{CMA08-90}$, (b) $\mathrm{C}_{12} \mathrm{CMA08-140}$, and (c) $\mathrm{C}_{12} \mathrm{CMA08-180}$. Unfilled and filled symbols are the data from SAXS and SLS measurements, respectively. Curves are the theoretical values described in the text: Solid red curve, mixture of monodisperse sphere droplets and wormlike chains; solid blue curve, mixture of polydisperse $(Ð=1.2)$ sphere droplets and wormlike 
chains; dashed black curves, wormlike chain of which parameters are summarized in Table 1. Polymer mass concentration range to obtain the infinite dilution data was between 5 and $20 \mathrm{mg}$ $\mathrm{mL}^{-1}$.

Scattering Profile for Hydrophobic $\mathrm{C}_{12} \mathrm{CMA}$ Samples. Since concentration dependence of $R(q) / K c$ is only detectable at low- $q$ range (but not significant in the scale of Figure 3 ) as in the case of relatively hydrophilic samples, aggregation state does not also depend on $c$ in the current concentration range. Figure 3 illustrates the $q$ dependence of $[R(q) / K c]_{c \rightarrow 0}$ for $\mathbf{C 1 2}_{12} \mathbf{C M A 2 3 - 3 5}$, C12CMA23-90, and $\mathbf{C}_{12} \mathbf{C M A 3 9 - 9 0 .}$. As in the case of the data points in Figure 2, the $[R(q) /$ $K c]_{c \rightarrow 0}$ data from SAXS for the three samples at the lowest $q$ are fairly close to those for $\left[R_{2}(q) /\right.$ $K c]_{c \rightarrow 0}$ from light scattering. Another significant feature of the scattering profile from the three samples in Figure 3 is that a significant minimum is found at $q=1 \mathrm{~nm}^{-1}$, suggesting the hydrophobic core with low electron density in the particle. From the comparison of the data in Figures 2 and 3, we roughly concluded that threshold $D S_{\mathrm{C} 12}$ to find hydrophobic core is around $D S_{\mathrm{C} 12}=0.1-0.2$.

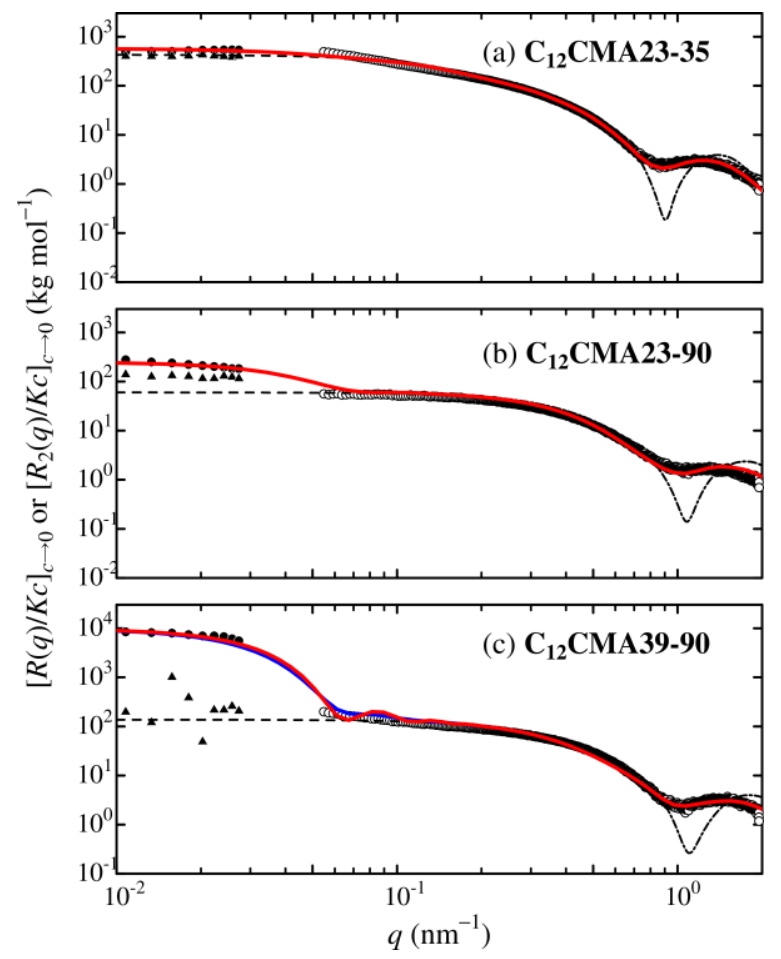

Figure 3. $q$ dependence of $[R(q) / K c]_{c \rightarrow 0}$ (circles) and $\left[R_{2}(q) / K c\right]_{c \rightarrow 0}$ (triangles) for relatively hydrophobic $\mathrm{C}_{12} \mathrm{CMA}$ samples in $150 \mathrm{mM}$ aqueous $\mathrm{NaCl}$ at $25{ }^{\circ} \mathrm{C}$. (a) $\mathbf{C 1}_{12} \mathbf{C M A 2 3 - 3 5}$, (b) C12CMA23-90, and (c) C12CMA39-90. Unfilled and filled circles are the data from SAXS and SLS measurements, respectively. Curves are the theoretical values described in the text: Solid red curve, mixture of monodisperse sphere droplets and double cylinders; solid blue curve, mixture of polydisperse $(\nexists=1.2)$ sphere droplets and double cylinders; black dashed curves, double cylinders with a certain diameter dispersion; black dotted dashed curves, double cylinders with $\sigma_{\text {cyl }}=0$. Their parameters are summarized in Table 1. Concentration range to obtain the infinite dilution data was between 5 and $20 \mathrm{mg} \mathrm{mL}^{-1}$. 
Fluorescence from Pyrene as a Probe. The obtained ratio $I_{3} / I_{1}$ for $\mathrm{C}_{12} \mathrm{CMA}$ samples are plotted against $D S_{\mathrm{C} 12}$ in Figure 4. As is well known that the ratio significantly reflects the hydrophobic environments. The value of $I_{3} / I_{1}$ was reported to be 0.6 in bulk water ${ }^{17}$ and 0.96 in aqueous micelle solution of sodium dodecyl sulfate. ${ }^{18}$ The $I_{3} / I_{1}$ data in Figure 4 increase from 0.7 for $D S_{\mathrm{C} 12}=0$ with increasing $D S_{\mathrm{C} 12}$ and reach 0.9 when $D S_{\mathrm{C} 12}=0.076$. This value is comparable to that for amphiphilic statistical copolymers bearing dodecyl hydrophobes ${ }^{19}$ whereas no significant nano-sized structure was found in the scattering profile in Figure 2 at high $q$ region, suggesting that pyrene molecules are located nearby the polysaccharide chain and/or inside the helical structure of the amylosic main chain. The ratio $I_{3} / I_{1}$ further increases and reaches around 1.1 at higher $D S_{\mathrm{C} 12}$. This clearly shows all $\mathrm{C}_{12} \mathrm{CMA}$ samples hydrophobic environment in aqueous solution and the hydrophobicity increases with increasing the fraction of hydrophobes in each polymer molecule while the existence micellar structure may not be decided only from the ratio $I_{3} / I_{1}$ since almost all $\mathrm{C}_{12} \mathrm{CMA}$ chains with $D S_{\mathrm{C} 12}=0.076$ behaves as simple wormlike chains in the saline as discussed below.

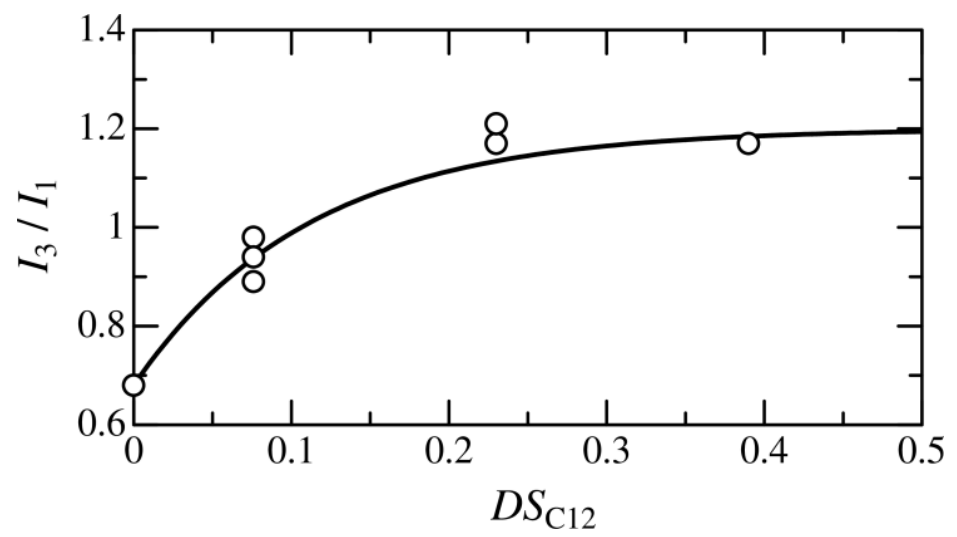

Figure 4. $D S_{\mathrm{C} 12}$ dependence of the ratio $I_{3} / I_{1}$ of intensities of the third $\left(\lambda_{0}=383 \mathrm{~nm}\right)$ to the first $\left(\lambda_{0}=372 \mathrm{~nm}\right)$ vibronic peaks for the pyrene with $\mathrm{C}_{12} \mathrm{CMA}$ or NaCMA samples in $150 \mathrm{mM}$ aqueous $\mathrm{NaCl}$ at $25^{\circ} \mathrm{C}$.

Analyses of the Scattering Profile of Relatively Hydrophilic $\mathrm{C}_{12} \mathrm{CMA}$ Samples. Here, we analyze the data in Figure 2 to elucidate molecular structure of $\mathrm{C}_{12} \mathrm{CMA}$ with $D S_{\mathrm{C} 12}=0.076$ in $150 \mathrm{mM}$ aqueous $\mathrm{NaCl}$. If we consider $\mathbf{C}_{\mathbf{1 2}} \mathbf{C M A 0 8 - 9 0 ,} \mathbf{C}_{\mathbf{1 2}} \mathbf{C M A 0 8 - 1 4 0}$, and $\mathbf{C}_{12} \mathrm{CMA08-180}$ have two components, 1 and 2 , in the saline, the normalized scattering intensity $[R(q) / K c]_{c \rightarrow 0}$ with no interparticle interference can be written as

$$
\left[\frac{R(q)}{K c}\right]_{c \rightarrow 0}=w_{1} M_{\mathrm{w}, 1} P_{1}(q)+\left(1-w_{1}\right) M_{\mathrm{w}, 2} P_{2}(q)
$$

where $w_{1}$ is the weight fraction of the component $1, M_{\mathrm{w}, 1}$ and $M_{\mathrm{w}, 2}$ are the weight-average molar mass of each component, and $P_{1}(q)$ and $P_{2}(q)$ are the respective particle scattering functions. As is seen from Figure 2, the normalized scattering intensities $\left[R_{2}(q) / K c\right]_{c \rightarrow 0}$ are quite similar each other $\left(\sim 40 \mathrm{~kg} \mathrm{~mol}^{-1}\right)$. Since this value is not very different from that for ESA50K $\left(M_{\mathrm{v}}=49.7 \mathrm{~kg}\right.$ $\mathrm{mol}^{-1}$, we assume the component 2 is single molecule. Applying the touched-bead wormlike chain model for the component $2, P_{2}(q)$ is expressed as ${ }^{20-21}$ 


$$
\begin{aligned}
& P_{2}(q)=\left[F_{0 \mathrm{~b}}(q d)\right]^{2} \frac{2}{L^{2}} \int_{0}^{L} \lambda(L-t) I\left(\lambda^{-1} q ; \lambda t\right) d t \\
& F_{0 \mathrm{~b}}(y)=3\left(\frac{2}{y}\right)^{3}\left(\sin \frac{y}{2}-\frac{y}{2} \cos \frac{y}{2}\right)
\end{aligned}
$$

where $L, d$, and $\lambda^{-1}$ are the contour length, the bead diameter, and the Kuhn segment length of the wormlike chain, respectively. The last parameter $\left(\lambda^{-1}\right)$ is a measure of the chain stiffness and twice the persistence length. The characteristic function $I\left(\lambda^{-1} q ; \lambda t\right)$ can be calculated in terms of the approximate expression by Nakamura and Norisuye. ${ }^{20,22}$ Now, we also assume that the component 1 is modeled by spherical droplets consisting of uniform concentrated $\mathrm{C}_{12} \mathrm{CMA}$ solutions with the concentration of $c_{\text {sph. }}$. This assumption is reasonable because such large droplets were also found for some polymer micelles consisting of weakly segregated block copolymers. ${ }^{23-25}$ Since we assume the diameter of the component 1 is substantially identical to the same as $2 R_{\mathrm{H}, 1}$ from DLS measurements, the total molar mass of the $\mathrm{C}_{12} \mathrm{CMA}$ molecules in each spherical particle is estimated to be $4 \pi R_{\mathrm{H}, 1}{ }^{3} N_{\mathrm{A}} c_{\mathrm{sph}} / 3$ with $N_{\mathrm{A}}$ being the Avogadro number. The first term of the right hand of eq 1 may therefore be written as

$$
\begin{aligned}
& w_{1} M_{\mathrm{w}, 1} P_{1}(q)=\frac{4 \pi R_{\mathrm{H}, 1}^{3} N_{\mathrm{A}} c_{\mathrm{sph}} w_{1}}{3} \Phi^{2}\left(q R_{\mathrm{H}, 1}\right) \\
& \Phi(x)=\frac{3(\sin x-x \cos x)}{x^{3}}
\end{aligned}
$$

Thus, $\left[R_{2}(q) / K c\right]_{c \rightarrow 0}$ on eq 1 can be calculated with the six parameters, $L, \lambda^{-1}, d, c_{\mathrm{sph}}, w_{1}$, and $M_{\mathrm{w}, 2}$. Since the first term on the right hand in eq 1 abruptly decrease with increasing $q$, the former three parameters $\left(L, \lambda^{-1}\right.$, and $d$ ) for the second term are unequivocally determined from the curve fitting procedure of the experimental data in the range of $0.1 \mathrm{~nm}^{-1} q<2 \mathrm{~nm}^{-1}$, see dashed curves in Figure 2. Since the Holtzer plot shown in Figure 5 for the $\mathrm{C}_{12} \mathrm{CMA}$ samples has typical feature of the wormlike chain, $L$ can be estimated from the horizontal region in Figure 5 around $q=1 \mathrm{~nm}^{-1}$. The chain stiffness can be estimated from the peak shape around $q=0.2 \mathrm{~nm}^{-1}$. Monotonic decrease of $\left[R_{2}(q) / K c\right]_{c \rightarrow 0}$ with increasing $q$ corresponds to the finite chain thickness regarding with $d$. The resultant parameters are summarized in Table 1. The hydrodynamic radius of the wormlike chains are calculated with the parameters from the Yamakawa-Yoshizaki theory ${ }^{26}$ to be 4.8, 4.1, and 4.1 nm for $\mathbf{C}_{12} \mathbf{C M A 0 8 - 9 0 ,} \mathbf{C}_{12} \mathrm{CMA08-140}$, and $\mathbf{C}_{\mathbf{1 2}} \mathbf{C M A 0 8 - 1 8 0}$, respectively. They are consistent with the corresponding $R_{\mathrm{H}, 2}$ values in Table 1 . 


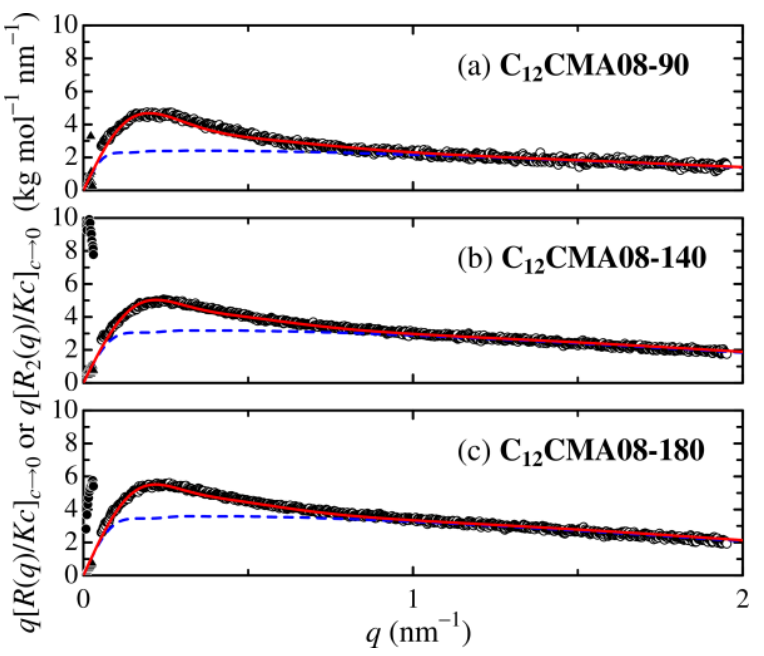

Figure 5. Holtzer plots, $q[R(q) / K c]_{c \rightarrow 0}$ or $q\left[R_{2}(q) / K c\right]_{c \rightarrow 0}$ vs $q$, for (a) C12 CMA08-90, (b) C12 CMA 08-140, and (c) $\mathbf{C}_{12}$ CMA08-180 in $150 \mathrm{mM}$ aqueous $\mathrm{NaCl}$ at $25{ }^{\circ} \mathrm{C}$. The data are the same as those in Figure 2. Solid curves are the theoretical values of the touched bead wormlike chains with the parameters in Table 1. Dashed curves are the rod-limiting values.

While the residual three parameters $\left(c_{\mathrm{sph}}, w_{1}\right.$, and $\left.M_{\mathrm{w}, 2}\right)$ cannot be determined independently, the two combined parameters, $\left(1-w_{1}\right) M_{\mathrm{w}, 2}$ and $4 \pi R_{\mathrm{H}, 1}{ }^{3} N_{\mathrm{A}} c_{\mathrm{sph}} w_{1} / 3$ (or $c_{\mathrm{sph}} w_{1}$ ), were estimated from the left end of dashed and solid curves in Figure 2, respectively. The small damped oscillation is only found for theoretical values. This is most likely because actual sphere like droplets have finite roughness on the surface and/or size distribution. If we consider the latter effect by a $\log$-normal distribution of the volume $V\left(=4 \pi R^{3} / 3\right)$ of the particles with $R$ being the radius, the z-average particle scattering function $P_{1, z}(q)$ of component 1 is expressed as

$$
\begin{aligned}
& P_{1, z}(q)=\frac{\int_{0}^{\infty} \Phi^{2}[q \sqrt[3]{3 V / 4 \pi}] V w(V) d V}{\int_{0}^{\infty} V w(V) d V} \\
& w(V)=\frac{1}{\sqrt{2 \pi} \sigma_{\mathrm{sph}} V} \exp \left\{-\frac{\left[\ln \left(V / V_{\mathrm{m}}\right)\right]^{2}}{2 \sigma_{\mathrm{sph}}^{2}}\right\}
\end{aligned}
$$

where $V_{\mathrm{m}}$ and $\sigma_{\mathrm{sph}}$ are the parameters of the volume dispersion of the spherical droplets. If we choose $V_{\mathrm{m}}=4 \pi R_{\mathrm{H}, 1}{ }^{3} / 3$ and quite small $\sigma_{\mathrm{sph}}$ of 0.43 which corresponds to $D=1.2$, the resultant theoretical blue curve successfully reproduces the experimental data. In any event, the resultant $c_{\mathrm{sph}} w_{1}$ values were estimated to be $0.4-0.8 \mathrm{mg} \mathrm{mL}^{-1}$ somewhat depending on the sample. It is reasonably suppose that $c_{\text {sph }}$ should have relatively high value and even if we assume the relatively low $c_{\text {sph }}$ of $100 \mathrm{mg} \mathrm{mL}^{-1}, w_{1}$ is estimated to be the order of $10^{-3}$, suggesting the component 2 is dominant and another parameter $\left(1-w_{1}\right) M_{\mathrm{w}, 2}$ is substantially close to $M_{\mathrm{w}, 2}$. What needs to be emphasized is that experimental results only from DLS, the spectrum of $A\left(R_{\mathrm{H}, \mathrm{app}}\right)$ vs $R_{\mathrm{H}, \text { app }}$ (Figure 1), may focus only on the largest particles in solution even though it is not a major component as revealed in our previous paper. ${ }^{23}$ The evaluated $\left(1-w_{1}\right) M_{\mathrm{w}, 2}$ values $\left(40-44 \mathrm{~kg} \mathrm{~mol}^{-1}\right)$ are however quite smaller than the calculated values $\left(75-99 \mathrm{~kg} \mathrm{~mol}^{-1}\right)$ from the $M_{\mathrm{v}}$ value of ESA50K $(=49.7$ $\mathrm{kg} \mathrm{mol}^{-1}$ ) and $M_{0}$ in Table 1. This is most likely due to the scission of polymer chains during the 
synthesis and/or the preferential recover of shorter chain samples. In any event, this difference does not affect the current analysis because it is free from the calculated molar mass.

Assuming $w_{1}=1$, we can estimate the helix pitch per residue $h\left(=L M_{\mathrm{w}, 2} / M_{0}\right)$ for the

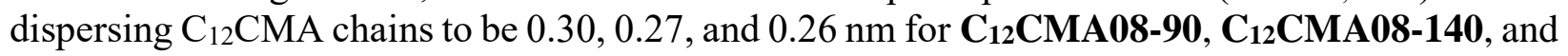
C12 CMA08-180, respectively. These $h$ values are somewhat smaller than those for amylose in DMSO $(0.33 \mathrm{~nm})^{2}$ and sodium carboxymethyamylose $(\mathrm{NaCMA})$ with $D S_{\mathrm{CM}}=0.64$ in a saline $(0.37 \mathrm{~nm}){ }^{27}$ It should be noted that the assumption of $w_{1}=1$ makes $h$ slight overestimate. This specific conformation is most likely because the interaction between hydrophobic groups and amylosic main chain induces locally helical structure of the main chain. This is reasonable because amylose may form complex with fatty acids in the crystalline state. ${ }^{28}$ If we consider continuous 9 pyranose rings for each dodecyl group form helical structure with $h$ of $0.13 \mathrm{~nm}$ for $\mathrm{V}$-amylose ${ }^{29}$ and the $h$ value of the other part is assumed to be $0.37 \mathrm{~nm}$, the mean helix pitch per residue is estimated to be $0.21 \mathrm{~nm}$ for the three samples, suggesting that some part of the side dodecyl groups form inclusion complex with the amylosic main chain. The chain stiffness parameters for these samples are from 7 to $9 \mathrm{~nm}$ slightly increasing function of $D S_{\mathrm{CM}}$. These values are somewhat larger than those for amylose in water ${ }^{3,30-31}\left(\lambda^{-1}=2.4 \mathrm{~nm}\right)$ and NaCMA $\left(D S_{\mathrm{CM}}=0.64\right)$ in $10 \mathrm{mM}$ aqueous $\mathrm{NaCl}\left(\lambda^{-1}=5 \mathrm{~nm}\right),{ }^{27}$ suggesting that above-mentioned helical part somewhat stiffens the main chain. In summary, $\mathrm{C}_{12} \mathrm{CMA}$ samples with a few hydrophobic groups $\left(D S_{\mathrm{C} 12}=0.076\right)$ in $150 \mathrm{mM}$ aqueous $\mathrm{NaCl}$ tend to form large aggregate, but almost chains disperse in solution as illustrated in Figure 6.

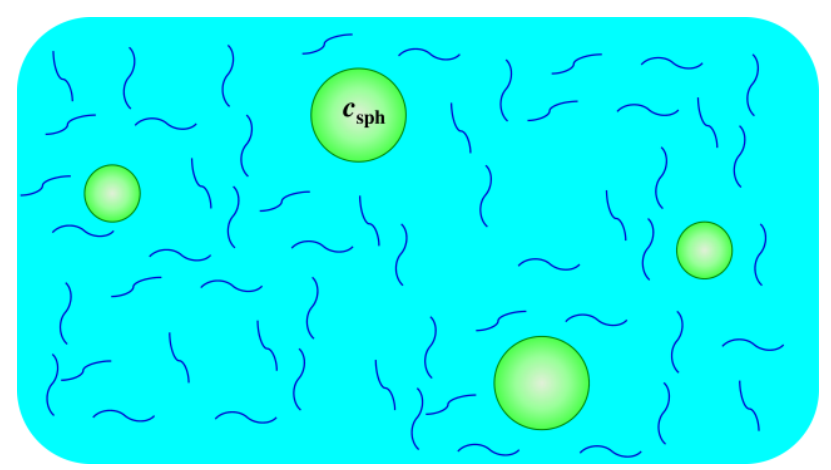

Figure 6. Schematic illustration of spherical droplets and dispersed relatively hydrophilic $\mathrm{C}_{12} \mathrm{CMA}$ chains $\left(D S_{\mathrm{C} 12}=0.076\right)$ in aqueous $\mathrm{NaCl}$.

Analyses of the Scattering Profile of Relatively Hydrophobic $\mathrm{C}_{12} \mathrm{CMA}$ Samples. As described above, $q$ dependence of $\left[R_{2}(q) / K c\right]_{c \rightarrow 0}$ for $\mathbf{C}_{12}$ CMA23-35, C12CMA23-90, and C12 CMA39-90 in Figure 3 is fairly close to the lower end of SAXS intensity. As in the case of hydrophilic $\mathrm{C}_{12} \mathrm{CMA}$ samples, DLS results show that at least two different sized components should be considered in the saline. While a shallow minimum at ca. $q=1 \mathrm{~nm}^{-1}$ indicates hydrophobic core with low electron density, gradual decreasing behavior between 0.1 and $0.5 \mathrm{~nm}^{-1}$ suggests the anisotropy of the particle and therefore it is hard to be explained in terms of simple spherical object. We thus choose concentric double cylinder model of which particle scattering function $P_{2}(q)$ is expressed as ${ }^{32}$

$$
P_{2}(q)=P_{\text {cyl }}\left(q ; \frac{L_{\text {cyl }}}{2}, \frac{d_{\text {cyl }}}{2}, \frac{d_{\text {cyl }} r_{\mathrm{oi}}}{2}, f_{\mathrm{oi}}\right)
$$




$$
\begin{aligned}
& P_{\text {cyl }}\left(q ; l, r_{\mathrm{o}}, r_{\mathrm{i}}, f_{\mathrm{oi}}\right)=\int_{0}^{\pi / 2}\left[\frac{r_{\mathrm{o}}^{2} G\left(q ; l, r_{\mathrm{o}}, \beta\right)+f_{\mathrm{oi}} r_{\mathrm{i}}^{2} G\left(q ; l, r_{\mathrm{i}}, \beta\right)}{r_{\mathrm{o}}{ }^{2}+f_{\mathrm{oi}} r_{\mathrm{i}}^{2}}\right]^{2} \sin \beta \mathrm{d} \beta \\
& G(q ; l, r, \beta)=\frac{\sin (q l \cos \beta) 2 J_{1}(q r \sin \beta)}{q^{2} l r \sin \beta \cos \beta}
\end{aligned}
$$

where $L_{\mathrm{cyl}}, d_{\mathrm{cyl}}$, and $r_{\mathrm{oi}}$, are the length, (outer) diameter, and the ratio of outer to inner diameters of the cylinder, respectively, as illustrated in Figure 7. The parameter $f_{\text {oi }}$ is related to the excess electron densities $\Delta \rho_{\mathrm{i}}$ and $\Delta \rho_{\mathrm{o}}$ of inner and outer cylinders as

$$
f_{\mathrm{oi}}=\frac{\Delta \rho_{\mathrm{i}}-\Delta \rho_{\mathrm{o}}}{\Delta \rho_{\mathrm{o}}}
$$

When we consider the hydrophobic core mainly consists of dodecyl group and it has lower electron density than solvent, and furthermore, total electron density of $\mathrm{C}_{12} \mathrm{CMA}$ is higher $(\Delta z>0)$ than the solvent, it is reasonably suppose that the parameter $f_{\mathrm{oi}}$ is negative. If we assume the larger component is modeled by the sphere like droplet as in the case of the hydrophilic $\mathrm{C}_{12} \mathrm{CMA}$, the scattering profile can be calculated in terms of eqs $1,4,5,8-10$ with the parameters $L_{\mathrm{cyl}}, d_{\mathrm{cyl}}, r_{\mathrm{oi}}$, $f_{\mathrm{oi}}, c_{\mathrm{sph}}, w_{1}$, and $M_{\mathrm{w}, 2}$. As is the case with the former case, we can estimate the two combined parameters, $c_{\mathrm{sph}} w_{1}$ and $\left(1-w_{1}\right) M_{\mathrm{w}, 2}$, from the flat regions at the left end and around $0.05-0.2 \mathrm{~nm}^{-1}$, respectively, in Figure 3. The obtained $c_{\mathrm{sph}} w_{1}$ values listed in Table 1 indicate that the weight fraction $w_{1}$ of the larger component is less than $1 \%$ when we assume $c_{\text {sph }}>50 \mathrm{mg} \mathrm{mL}^{-1}$ for C12CMA23-35 and $\mathbf{C}_{12}$ CMA23-90 whereas that for the more hydrophobic $\mathbf{C}_{12} \mathbf{C M A 3 9 - 9 0}$ is quite higher: The value is estimated to be $w_{1}=0.24$ or 0.061 when assuming $c_{\text {sph }}=50$ or $200 \mathrm{mg} \mathrm{mL}^{-1}$, respectively, suggesting, larger droplets become more significant when the hydrophobicity is higher. The residual four parameters, $L_{\mathrm{cyl}}, d_{\mathrm{cyl}}, r_{\mathrm{oi}}$, and $f_{\mathrm{oi}}$, are those for the double cylinder. If we choose the parameters listed in Table 1, the resultant dot-dashed curves in Figure 3 can explain the minimum $q$ position, but the theoretical minimum is significantly deeper than that for the experimental value. This is most likely due to the distribution of diameters and/or the roughness of the interface of the cylinders. For the simplicity of the discussion, we introduce the following log-normal distribution for the radius of the cylinder $r$. Then, the $z$-average particle scattering function $P_{2, z}(q)$ is expressed as

$$
\begin{aligned}
& P_{2, z}(q)=\frac{\int_{0}^{\infty} P_{\mathrm{cyl}}\left(q ; \frac{L_{\mathrm{cyl}}}{2}, \sqrt{V / \pi L_{\mathrm{cyl}}}, r_{\mathrm{oi}} \sqrt{V / \pi L_{\mathrm{cyl}}}, f_{\mathrm{oi}}\right) V w^{\prime}(V) d V}{\int_{0}^{\infty} V w^{\prime}(V) d V} \\
& w^{\prime}(V)=\frac{1}{\sqrt{2 \pi} \sigma_{\mathrm{cyl}} V} \exp \left\{-\frac{\left[\ln \left(V / V_{\mathrm{m}, \mathrm{cyl}}\right)\right]^{2}}{2 \sigma_{\mathrm{cyl}}^{2}}\right\}
\end{aligned}
$$

Here, $V_{\mathrm{m} \text {,cyl }}\left(\equiv \pi L_{\mathrm{cyl}} d_{\mathrm{cyl}}{ }^{2} / 4\right)$ and $\sigma_{\mathrm{cyl}}$ are the parameters of the volume dispersion of the cylinders. When we choose $\sigma_{\text {cyl }}=0.4$ or 0.5 ( $(D=1.17$ or 1.28$)$, well-fitted theoretical curves can be shown 
in Figure 3 with the parameters of $L_{\mathrm{cyl}}, d_{\mathrm{cyl}}, r_{\mathrm{oi}}$, and $f_{\mathrm{oi}}$. While the three parameters, $L_{\mathrm{cyl}}, d_{\mathrm{cyl}}$, and $\sigma_{\mathrm{cyl}}$, were uniquely be determined, $r_{\mathrm{oi}}$ and $f_{\mathrm{oi}}$ are significantly correlated each other; we could fairly estimate $r_{\mathrm{oi}}^{2} f_{\mathrm{oi}}$ as a fitting parameter when $r_{\mathrm{oi}}<0.5$. The obtained parameters are listed in Table 1. The resultant theoretical values in Figure 3 reproduce the experimental data almost quantitatively. The slight fluctuation for $\mathbf{C}_{12} \mathbf{C M A 3 9 - 9 0}$ around $q=0.7 \mathrm{~nm}^{-1}$ becomes smooth if polydispersity of the spherical droplet with eq 6 with $\sigma_{\text {sph }}=0.43$ (or $\oslash=1.2$ ). If we consider that hydrophobic core of polysoaps consisting of flexible vinyl polymers were discussed with spherical models by Borisov and Halperin, ${ }^{33-35}$ flower necklace model might be better for the current system. The shallower depression shown at ca. $q=1 \mathrm{~nm}^{-1}$ comparing with block copolymer micelles ${ }^{36-38}$ or alternative copolymer micelle ${ }^{39}$ however suggests that the spherically symmetric core model is not suitable for the current system. Indeed, the current scattering data can also be explained by the flower neckless model which is proposed for an alternative copolymer ${ }^{39-40}$ while quite large size distribution should be considered. This supports that the hydrophobic core of the current polysaccharide system has anisotropic shape. This is likely due to that the rigid part at which the main chain and a side dodecyl group form rodlike complex may yield anisotropic stacking structure. It should be however noticed that the detailed shape of the hydrophobic core is difficult to be determined only from scattering data.

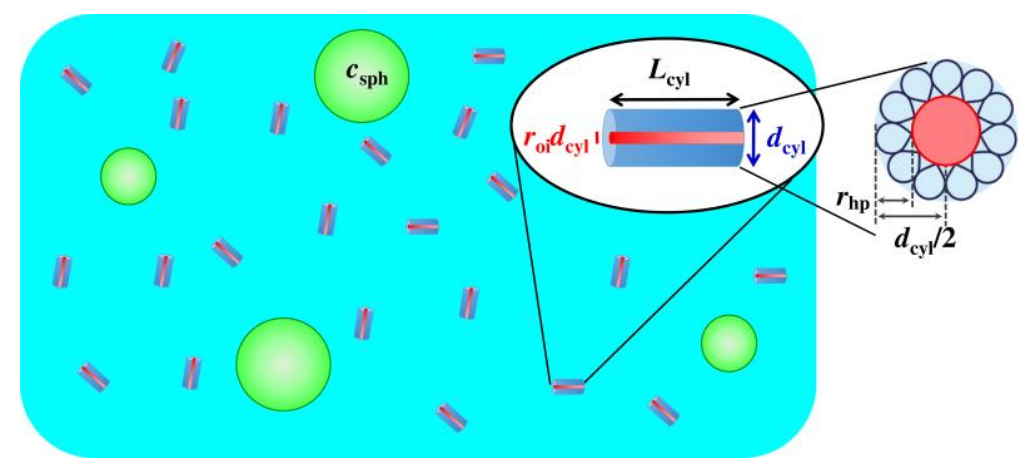

Figure 7. Schematic illustration of spherical droplets and dispersed relatively hydrophilic $\mathrm{C}_{12} \mathrm{CMA}$ chains $\left(D S_{\mathrm{C} 12}=0.2-0.4\right)$ in aqueous $\mathrm{NaCl}$. as $^{41}$

The hydrodynamic radius $R_{\mathrm{H}, \mathrm{cyl}}$ of the straight cylinder (or cylindrical micelle) is expressed

$$
R_{\mathrm{H}, \mathrm{cyl}}=\frac{L_{\mathrm{cyl}}}{2}\left[\ln \left(\frac{L_{\mathrm{cyl}}}{d_{\mathrm{cyl}}}\right)+0.312+0.65\left(\frac{d_{\mathrm{cyl}}}{L_{\mathrm{cyl}}}\right)-0.100\left(\frac{d_{\mathrm{cyl}}}{L_{\mathrm{cyl}}}\right)^{2}\right]^{-1}
$$

The values of $R_{\mathrm{H}, \mathrm{cyl}}$ for $\mathbf{C}_{\mathbf{1 2}} \mathbf{C M A 2 3 - 3 5}, \mathbf{C}_{\mathbf{1 2}} \mathbf{C M A 2 3 - 9 0}$, and $\mathbf{C}_{\mathbf{1 2}} \mathbf{C M A 3 9 - 9 0}$ are calculated to be

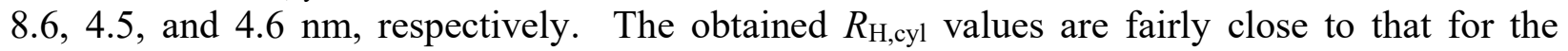
corresponding $R_{\mathrm{H}, 2}$ in Table 1 . A possible reason why the experimental $R_{\mathrm{H}}$ is $10-20 \%$ larger than $R_{\mathrm{H}, \mathrm{cyl}}$ is that the electron density profile of the shell region is not uniform.

According to Kawata et al. ${ }^{19}$ and Ueda et al., ${ }^{40}$ structure of flower micelles of random and alternative copolymers are determined by the chain stiffness of the polymer, that is, thickness of the hydrophilic shell $r_{\mathrm{hp}}$ can be estimated to be $0.31 \lambda^{-1}$ on the basis of the ring closure probability of the wormlike chains. ${ }^{26}$ When we assume $f_{\mathrm{oi}}=-4$ for a previously investigated amphiphilic 
polymer, ${ }^{39}$ the inner diameter of the cylinder is estimated to be $1.4-1.6 \mathrm{~nm}$, which is close to the length of the extended dodecyl group. Furthermore, we estimated the thickness $r_{\text {hp }}$ of hydrophilic shell defined as $\left(1-r_{\mathrm{oi}}\right) d_{\mathrm{cyl}} / 2$ to be $1.9-2.7 \mathrm{~nm}$ slightly depending on the sample, which can be predicted from the chain stiffness of the amylosic chains consisting of hydrophilic part. Indeed, we can obtain $r_{\mathrm{hp}}=0.31 \lambda^{-1}=2.5 \pm 0.4 \mathrm{~nm}$ when we choose $\lambda^{-1}$ determined for the three hydrophilic $\mathrm{C}_{12} \mathrm{CMA}\left(\lambda^{-1}=8 \pm 1 \mathrm{~nm}\right)$. On the other hand, if we assume the hydrophobic core has the same density as that for dodecane $\left(\rho_{\text {dodecane }}=0.75 \mathrm{~g} \mathrm{~mL}^{-1}\right)$, molar mass of the hydrophobic core is estimated from $\pi r_{\mathrm{oi}}{ }^{2} d_{\mathrm{cyl}}{ }^{2} L_{\text {cyl }} \rho_{\text {dodecane }} N_{\mathrm{A}} / 4$ to be $31,9.6$, and $9.9 \mathrm{~kg} \mathrm{~mol}^{-1}$ for $\mathbf{C 1 2} \mathbf{C M A 2 3 - 3 5}$, C12CMA23-90, and $\mathbf{C 1 2}_{12} \mathbf{C M A 3 9 - 9 0 ,}$, respectively. These values are the same order as 74, 9.4, and $40 \mathrm{~kg} \mathrm{~mol}^{-1}$ calculated from $M_{\text {dodecyl }} D S_{\mathrm{C} 12} M_{\mathrm{w}, 2} / M_{0}$ when assuming $c_{\mathrm{sph}}=50 \mathrm{mg} \mathrm{mL}^{-1}$ (this value is insignificant) where $M_{\text {dodecyl }}$ is the molar mass of the dodecyl group $0.169 \mathrm{~kg} \mathrm{~mol}^{-1}$, thus reasonable. We may conclude from the results that the course grained model consisting of large droplets and anisotropic micelles is well explained the scattering data for the three $\mathrm{C}_{12} \mathrm{CMA}$ samples and therefore, relatively hydrophobic $\mathrm{C}_{12} \mathrm{CMA}$ samples is a candidate of for functional polymeric micelles.

\section{Conclusions}

We demonstrated that amylose based amphiphilic copolymer samples which have both hydrophobic dodecyl group and hydrophilic sodium carboxymethyl group form hydrophobic core when $D S_{\mathrm{C} 12}$ is 0.23 and 0.39 . In other words, amylose based amphiphilic polymer micelle is successfully obtained while the micelle structure is rather anisotropic comparing with the vinyl polymer based alternative amphiphilic copolymer. ${ }^{39}$ Even though no hydrophobic core was found for the $\mathrm{C}_{12} \mathrm{CMA}$ samples with $D S_{\mathrm{C} 12}$ being 0.076 , appreciably shorter contour length and somewhat higher chain stiffness was revealed, suggesting that the side dodecyl groups induce the helical structure of the main chain. This higher chain stiffness may be important for the anisotropic hydrophobic core found for higher $D S_{\mathrm{C} 12}$ samples.

\section{Supporting Information}

The Supporting Information is available free of charge on the ACS Publications website. ${ }^{1} \mathrm{H}$ NMR spectra.

Acknowledgements. The authors thank Dr. Noboru Ohta (SPring-8), Prof. Nobutaka Shimizu (KEK), and Prof. Noriyuki Igarashi (KEK) for SAXS measurements. The synchrotron radiation experiments were performed at the BL40B2 in SPring-8 with the approval of the Japan Synchrotron Radiation Research Institute (JASRI) (Proposal Nos. 2014B1087, 2014B1715, 2015A1179, 2015B1100, and 2016B1088) and at the BL-10C beamline in KEK-PF (2013G516). This work was partly supported by JSPS KAKENHI Grant Numbers JP17K05884 and JP18H02020.

\section{References}

1. Burchard, W. Light Scattering from Polysaccharides as Soft Materials. In Soft Matter Characterization, Borsali, R.; Pecora, R., Eds. Springer Netherlands: 2008; pp 463-603.

2. Nakanishi, Y.; Norisuye, T.; Teramoto, A.; Kitamura, S. Conformation of Amylose in Dimethyl-Sulfoxide. Macromolecules 1993, 26, 4220-4225. 
3. Norisuye, T. Viscosity Behavior and Conformation of Amylose in Various Solvents. Polym. J. 1994, 26, 1303-1307.

4. Shimada, J.; Kaneko, H.; Takada, T.; Kitamura, S.; Kajiwara, K. Conformation of Amylose in Aqueous Solution: Small-Angle X-ray Scattering Measurements and Simulations. $J$. Phys. Chem. B 2000, 104, 2136-2147.

5. $\quad$ Kitamura, S.; Suzuki, S. Starch and Dextran. In Encyclopedia of Polymeric Nanomaterials, Kobayashi, S.; Müllen, K., Eds. Springer Berlin Heidelberg: Berlin, Heidelberg, 2015; pp 2249-2254.

6. $\quad$ Putaux, J. L.; Nishiyama, Y.; Mazeau, K.; Morin, M.; Cardoso, M. B.; Chanzy, H. Helical Conformation in Crystalline Inclusion Complexes of V-Amylose: A Historical Perspective. Polymer-Solvent Complexes and Intercalates - Polysolvat 8 2011, 303, 1-9.

7. Sasaki, Y.; Akiyoshi, K. Self-assembled Nanogel Engineering for Advanced Biomedical Technology. Chem. Lett. 2012, 41, 202-208.

8. Koda, Y.; Sasaki, Y.; Akiyoshi, K. Formation and Function of Nanogels by SelfAssembly of Associating Graft Copolymers. Kobunshi Ronbunshu 2016, 73, 166-174.

9. $\quad$ Liu, Z.; Jiao, Y.; Wang, Y.; Zhou, C.; Zhang, Z. Polysaccharides-based Nanoparticles as Drug Delivery Systems. Adv Drug Deliv Rev 2008, 60, 1650-62.

10. Terao, K.; Fujii, T.; Tsuda, M.; Kitamura, S.; Norisuye, T. Solution Properties of Amylose Tris(phenylcarbamate): Local Conformation and Chain Stiffness in 1,4-Dioxane and 2Ethoxyethanol. Polym. J. 2009, 41, 201-207.

11. Heinze, T.; Pfeiffer, K.; Lazik, W. Starch Derivatives with High Degree of Functionalization. III. Influence of Reaction Conditions and Starting Materials on Molecular Structure of Carboxymethyl Starch. J. Appl. Polym. Sci. 2001, 81, 2036-2044.

12. Terao, K.; Kanenaga, R.; Sato, T.; Mizuno, K.; Bächinger, H. P. Complex Formation of Collagen Model Peptides with Polyelectrolytes and Stabilization of the Triple Helical Structure. Macromolecules 2012, 45, 392-400.

13. Okumoto, M.; Terao, K.; Nakamura, Y.; Norisuye, T.; Teramoto, A. Excluded-volume Effects in Star Polymer Solutions: Four-arm Star Polystyrene in Cyclohexane near the Theta Temperature. Macromolecules 1997, 30, 7493-7499.

14. Jinbo, Y.; Teranuma, O.; Kanao, M.; Sato, T.; Teramoto, A. Light-scattering Study of Semiflexible Polymer Solutions. 4. $n$-Hexane Solutions of Poly(n-hexyl isocyanate). Macromolecules 2003, 36, 198-203.

15. Furusawa, K.; Terao, K.; Nagasawa, N.; Yoshii, F.; Kubota, K.; Dobashi, T. Nanometersized Gelatin Particles Prepared by Means of Gamma-ray Irradiation. Colloid. Polym. Sci. 2004, 283, 229-233.

16. Glatter, O.; Kratky, O. Small Angle X-ray Scattering. Academic Press: London, 1982.

17. Kalyanasundaram, K.; Thomas, J. K. Environmental Effects on Vibronic Band Intensities in Pyrene Monomer Fluorescence and Their Application in Studies of Micellar Systems. J. Am. Chem. Soc. 1977, 99, 2039-2044.

18. Lianos, P.; Zana, R. Use of Pyrene Excimer Formation to Study the Effect of Sodium Chloride on the Structure of Sodium Dodecyl Sulfate Micelles. J. Phys. Chem. 1980, 84, 33393341.

19. Kawata, T.; Hashidzume, A.; Sato, T. Micellar Structure of Amphiphilic Statistical Copolymers Bearing Dodecyl Hydrophobes in Aqueous Media. Macromolecules 2007, 40, 11741180 . 
20. Nakamura, Y.; Norisuye, T. Scattering Function for Wormlike Chains with Finite Thickness. J. Polym. Sci., Part. B: Polym. Phys. 2004, 42, 1398-1407.

21. Burchard, W.; Kajiwara, K. The Statistics of Stiff Chain Molecules. I. The Particle Scattering Factor. Proc. R. Soc. London, Ser. A 1970, 316, 185-199.

22. Nakamura, Y.; Norisuye, T. Brush-Like Polymers. In Soft Matter Characterization, Borsali, R.; Pecora, R., Eds. Springer Netherlands: 2008; pp 235-286.

23. Sato, T.; Tanaka, K.; Toyokura, A.; Mori, R.; Takahashi, R.; Terao, K.; Yusa, S. SelfAssociation of a Thermosensitive Amphiphilic Block Copolymer Poly(N-isopropylacrylamide)b-poly(N-vinyl-2-pyrrolidone) in Aqueous Solution upon Heating. Macromolecules 2013, 46, 226-235.

24. Takahashi, R.; Sato, T.; Terao, K.; Qiu, X. P.; Winnik, F. M. Self-association of a Thermosensitive Poly(alkyl-2-oxazoline) Block Copolymer in Aqueous Solution.

Macromolecules 2012, 45, 6111-6119.

25. Takahashi, R.; Sato, T.; Terao, K.; Yusa, S.-i. Intermolecular Interactions and SelfAssembly in Aqueous Solution of a Mixture of Anionic-Neutral and Cationic-Neutral Block Copolymers. Macromolecules 2015, 48, 7222-7229.

26. Yamakawa, H.; Yoshizaki, T. Helical Wormlike Chains in Polymer Solutions, 2nd ed. Springer: Berlin, Germany, 2016.

27. Terao, K.; Kanenaga, R.; Yoshida, T.; Mizuno, K.; Bächinger, H. P. Temperature Induced Complex Formation-deformation Behavior of Collagen Model Peptides and Polyelectrolytes in Aqueous Solution. Polymer 2015, 64, 8-13.

28. Le, C. A.; Choisnard, L.; Wouessidjewe, D.; Putaux, J. L. Polymorphism of Crystalline Complexes of V-amylose with Fatty Acids. Int. J. Biol. Macromol. 2018, 119, 555-564.

29. Winter, W. T.; Sarko, A. Crystal and Molecular Structure of V-anhydrous Amylose. Biopolymers 1974, 13, 1447-1460.

30. Burchard, W. Das Viskositatsverhalten Von Amylose in Verschiedenen Losungsmitteln .24. Makromol. Chem. 1963, 64, 110-125.

31. Jiang, X. Y.; Kitamura, S.; Sato, T.; Terao, K. Chain Dimensions and Stiffness of Cellulosic and Amylosic Chains in an Ionic Liquid: Cellulose, Amylose, and an Amylose Carbamate in BmimCl. Macromolecules 2017, 50, 3980-3985.

32. Livsey, I. Neutron-Scattering from Concentric Cylinders - Intraparticle Interference Function and Radius of Gyration. J. Chem. Soc. Faraday Trans. 2 1987, 83, 1445-1452.

33. Borisov, O. V.; Halperin, A. Micelles of Polysoaps. Langmuir 1995, 11, 2911-2919.

34. Borisov, O. V.; Halperin, A. Micelles of Polysoaps: The Role of Bridging Interactions. Macromolecules 1996, 29, 2612-2617.

35. Borisov, O. V.; Halperin, A. Polysoaps: Extension and Compression. Macromolecules 1997, 30, 4432-4444.

36. Pedersen, J. S.; Gerstenberg, M. C. Scattering Form Factor of Block Copolymer Micelles. Macromolecules 1996, 29, 1363-1365.

37. Pedersen, J. S. Analysis of Small-angle Scattering Data from Colloids and Polymer Solutions: Modeling and Least-squares Fitting. Adv. Colloid Interface Sci. 1997, 70, 171-210.

38. Narita, T.; Terao, K.; Dobashi, T.; Nagasawa, N.; Yoshii, F. Preparation and Characterization of Core-shell Nanoparticles Hardened by Gamma-ray. Colloids and surfaces. B, Biointerfaces 2004, 38, 187-90. 
39. Uramoto, K.; Takahashi, R.; Terao, K.; Sato, T. Local and Global Conformations of Flower Micelles and Flower Necklaces Formed by an Amphiphilic Alternating Copolymer in Aqueous Solution. Polym. J. 2016, 48, 863-867.

40. Ueda, M.; Hashidzume, A.; Sato, T. Unicore-Multicore Transition of the Micelle Formed by an Amphiphilic Alternating Copolymer in Aqueous Media by Changing Molecular Weight. Macromolecules 2011, 44, 2970-2977.

41. Tirado, M. M.; Martínez, C. L.; de la Torre, J. G. Comparison of Theories for the Translational and Rotational Diffusion Coefficients of Rod-like Macromolecules. Application to Short DNA Fragments. J. Chem. Phys. 1984, 81, 2047-2052. 


\section{For Table of Contents Use Only}

Self-Assembly of Amphiphilic Amylose Derivatives in Aqueous Media Yuki Kameyama, Shinichi Kitamura, Takahiro Sato, and Ken Terao*

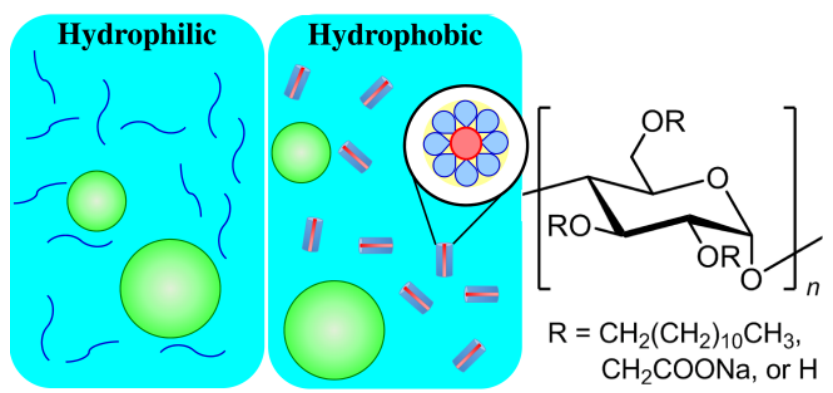

